\title{
The sources of house price changes in Malaysia
}

\begin{abstract}
Purpose: The purpose of this paper is to examine the house market in Malaysia from 2002 to 2015. Specifically, the macroeconomic determinants on the house price and house demand are investigated. Design/methodology/approach: Structural Vector Autoregressive Regression was adopted to estimate the unexpected changes in both house demand (residential transaction volume) and prices based on economic theoretical reasoning that consider shock from macroeconomic determinants. Findings: The transaction volume and real house prices respond to most of the macroeconomic shocks. While the impact of real gross domestic product (GDP) on house prices appears to be stronger and longer in comparison to other macroeconomic shocks, a 60 per cent change in house prices can be explained by real GDP regardless of whether it is in the short run or the long run. The studies also reveal that a positive effective exchange rate plays an important role when demonstrating the transaction volume. Moreover, monetary liquidity plays a major role in justifying the transaction volume. This implies that mortgage lending may have an impact on housing demand. Meanwhile, movements of house prices cannot be explained by the demand in quantity. This signifies that supply has a strong influence in determining the price. Research limitations/implications: This study has implications on policymakers of which the interest rate as a cooling measure might not be effective in the short run. The interest rate has very little impact on housing prices. Furthermore, policymakers should address the concerns on speculations, as the results reveal that monetary liquidity and the exchange rate have a strong impact on the housing demand. Originality/value: This study seeks to provide answers regarding the recent upsurge of Malaysian housing prices. Besides focusing on the house price changes, this study addresses the role of transaction volume while evaluating the house market, as housing prices are usually downwards rigid. Since the price and transaction volume are both related to the transaction activity, this study is significant and could be a good reflection on the actual demand behaviour in the residential market.
\end{abstract}

Keyword: Malaysia; House prices; Exchange rate; Structural VAR; Real GDP; Transaction volume 